\title{
IMPDH activity in
}

\section{thiopurine-treated}

patients

with inflammatory bowel

disease - relation to TPMT

activity and metabolite concentrations

\section{Correspondence}

Sofie Haglund, Research and Development in Laboratory Medicine, Laboratory Medicine, Ryhov Hospital, SE-551 85 Jönköping, Sweden.

Tel: +46 36322339

Fax: +46 36180073

E-mail: sofie.haglund@lj.se

\section{Keywords}

6-mercaptopurine, azathioprine, IMPDH, inflammatory bowel disease, inosine-5'-monophosphate dehydrogenase, thiopurine

\section{Received}

20 December 2006

Accepted

15 May 2007

Published OnlineEarly

27 July 2007

${ }^{1}$ Research and Development in Laboratory Medicine, Laboratory Medicine, Ryhov Hospital, ${ }^{2}$ Division
Gastroenterology and Hepatology, Department of Molecular and Clinical Medicine and ${ }^{3}$ Division of Clinical Pharmacology, Department of Medicine and Care, Linköping University, Linköping, Sweden

\section{WHAT IS ALREADY KNOWN ABOUT}

\section{THIS SUBJECT}

- Up to $30 \%$ of inflammatory bowel disease patients treated with the thiopurine drugs azathioprine and 6-mercaptopurine do not respond properly to therapy.

- Genetic variation in the polymorphic enzyme thiopurine S-methyltransferase (TPMT) is associated with adverse events if patients are treated with standard doses.

- However, not all adverse events or metabolite patterns can be explained by genetic variations in TPMT, therefore we investigated the role of another thiopurine-metabolizing enzyme, inosine-5'-monophosphate dehydrogenase (IMPDH).

\section{WHAT THIS STUDY ADDS}

- There was a negative correlation of mononuclear cell (MNC) IMPDH activity with red blood cell (RBC) 6-methylthioinosine 5'-monophosphate, but not with RBC 6-thioguanine nucleotide (6-TGN). - The results indicate either that measuring thiopurine metabolites in RBC, as is the current practice in clinical monitoring, is not an appropriate surrogate compartment for MNC metabolite concentrations, or that IMPDH in MNC is not as important a rate-limiting enzyme in the interconversion of thioinosine monophosphate to 6-TGN as has been hypothesized.

- All metabolite concentrations and enzymatic activities should preferably be measured in the same compartment.

\section{AIMS}

Azathioprine and 6-mercaptopurine are steroid-sparing drugs used in inflammatory bowel disease (IBD). The polymorphic enzyme thiopurine S-methyltransferase (TPMT) is of importance for thiopurine metabolism and occurrence of adverse events. The role of other thiopurinemetabolizing enzymes is less well known. This study investigated the role of inosine- $5^{\prime}$-monophosphate dehydrogenase (IMPDH), which is a key enzyme in the de novo synthesis of guanine nucleotides and also strategically positioned in the metabolic pathway of thiopurines.

\section{METHODS}

IMPDH was measured in 100 healthy blood donors. IMPDH, TPMT and metabolite concentrations were studied in 50 patients with IBD on stable thiopurine therapy. IMPDH activity was measured in peripheral blood mononuclear cells. TPMT activity, 6-methylthioinosine 5'-monophosphate (meTIMP) and 6-thioguanine nucleotide (6-TGN) concentrations were measured in red blod cells, which is the current practice in clinical monitoring of thiopurines. Enzyme activities were related to metabolite concentrations and clinical characteristics.

\section{RESULTS}

A wide range of IMPDH activity was observed both in healthy blood donors (median 13.1, range 4.7-24.2 $\mathrm{nmol} \mathrm{mg}^{-1}$ protein $\mathrm{h}^{-1}$ ) and IBD patients (median 14.0, range 7.0-21.7). There was a negative correlation between IMPDH activity and dose-normalized meTIMP concentrations $\left(r_{\mathrm{s}}=-0.31, P=0.03\right)$, but no evident correlation to 6-TGN concentration or the meTIMP/6-TGN ratio. There were no significant correlations between TPMT activity and metabolite concentrations.

\section{CONCLUSION}

Even though the meTIMP concentrations correlated inversely to the IMPDH activity, the role of IMPDH in balancing the formation of methylated and phosphorylated metabolites was not evident. Taken together, the results give cause to question established opinions about thiopurine metabolism. 
Treatment of inflammatory bowel disease (IBD) is currently based on aminosalicylates, corticosteroids, immunosuppressives, biologicals, antibiotics, nutritional support and surgery [1-4]. These therapies are limited by side-effects and may be inefficient in up to $30 \%$ of patients [5]. Steroidrefractory and steroid-dependent patients are at great risk of extensive bowel resections, even though surgery cannot cure IBD. These patients are qualified for more extensive immunosuppression and the most successful treatment so far has been thiopurine treatment with azathioprine (AZA) or 6-mercaptopurine (6-MP).

The thiopurines are subject to extensive metabolism with both activating and inactivating pathways. The drugs are activated intracellularly by hypoxanthine guanine phosphoribosyltransferase (HPRT1, EC 2.4.2.8). Phosphorylation to thioguanine nucleotides (6-TGN) and incorporation of 6-TGN in DNA has traditionally been regarded as the most important immunosuppressive mechanism [6, 7]. Competing pathways to 6-TGN formation are methylation regulated by the polymorphic enzyme thiopurine S-methyltransferase (TPMT, EC 2.1.1.67), and oxidation to thiouric acid by xanthine oxidase (EC 1.1.3.22) [6]. Both 6-MP and AZA also mediate their effects through inhibition of de novo purine biosynthesis by methylated metabolites (6-methylthioinsoine 5'-monophosphate, meTIMP) [8-11]. Recently, it has also been suggested that thioguanine-triphosphate (thio-GTP) interferes with the Rac1-Vav activation of guanosine $5^{\prime}$-diphosphate (GDP), promoting apoptosis [12], and that the drugs selectively inhibit the expression of inflammatory genes in activated T lymphocytes [13]. Studies have implicated the inosine triphosphate pyrophosphatase (ITPA, EC 3.6.1.19) $94 \mathrm{C} \rightarrow \mathrm{A}$ polymorphism in the development of adverse events of thiopurine drugs, such as rash, flu-like symptoms, pancreatitis and also leukopenia, but with divergent results [14-17].

The relevance of thiopurine-metabolizing enzymes other than TPMT to the clinical effects of these drugs has not been extensively evaluated.

Inosine 5'-monophosphate dehydrogenase (IMPDH, EC 1.1.1.205) is a key enzyme in the de novo synthesis of guanine nucleotides and is positioned at the branch point between adenine and guanine biosynthesis. IMPDH has the lowest activity of the purine enzymes $[18,19]$. It is also strategically positioned in the metabolic pathway of thiopurines $[6,19]$. IMPDH may be a significant rate-limiting enzyme in the metabolism of thiopurine drugs to 6-TGN, and its activity would be expected to correlate positively to 6-TGN concentrations and negatively to meTIMP concentrations.

The IMPDH enzyme is present in two isoforms encoded by two different genes, IMPDH1 and IMPDH2 [20], located on chromosomes 7 and 3, respectively [21-23]. High expression of IMPDH has been demonstrated in pancreas, kidney, colon and peripheral blood leucocytes compared with other tissues such as liver [24]. Increased enzymatic activity and IMPDH mRNA have been described in rapidly proliferating tumour cells and activated $\mathrm{T}$ lymphocytes $[18,20,25,26]$. In cells that are induced to differentiate, decreased activity and downregulated mRNA expression have been observed [26-28].

There are, to our knowledge, no data on IMPDH activity in relation to TPMT activity and the production of 6-TGN or meTIMP in IBD patients. The aims of this study were therefore to investigate (i) IMPDH activity in healthy blood donors and in IBD patients on stable thiopurine therapy, (ii) the relationships between the enzymatic activities of IMPDH and TPMT and metabolite formation, and (iii) whether the ITPA 94C $\rightarrow$ A polymorphism or concomitant 5-aminosalicylic acid (5-ASA) therapy had any impact on these relationships.

\section{Materials and methods}

\section{Study subjects}

The study was performed in 50 patients with IBD, Crohn's disease (CD; $n=25)$ and ulcerative colitis (UC; $n=25)$, of whom 23 were men aged 20-64 and 27 were women aged 19-80 years. Forty-six were of White and four of nonWhite ethnicity. All patients had been on stable treatment with thiopurines for at least 3.5 months without dose adjustment. The daily median dose of AZA $(n=39)$ was $2.06 \mathrm{mg} \mathrm{kg}^{-1}$ body weight per day (range $0.83-2.94$ ) and that of 6-MP $(n=11)$ was $0.92 \mathrm{mg} \mathrm{kg}^{-1}$ body weight per day (range 0.33-1.62). Patients on 6-MP had previously experienced side-effects on AZA but had been successfully changed to 6-MP.Twenty-four patients (CD six, UC 18) were on concomitant treatment with 5-ASA at $2325 \mathrm{mg} \mathrm{day}^{-1}$ (range 500-6750) and seven (UC four, CD three) were on steroids. Eight women and three men were smokers. None of the patients included in the study had received a blood transfusion within 4 months prior to the study.

Patient and disease characteristics were noted. Disease activity was measured at the time of sampling, using a Walmsley's index for UC and the Harvey-Bradshaw index for $C D[29,30]$. In both of these indices active disease was indicated by a score $>5$.

The reference group comprised 100 healthy blood donors (28 women aged 23-64 and 72 men aged 24-66 years), who were sampled in order to establish a reference interval for IMPDH activity. Their ethnicity was not registered.

Venous blood samples were obtained prior to the morning dose of thiopurine for routine blood chemistry, DNA extraction and IMPDH activity.

The study was reviewed and approved by the Ethics Committee at Linköping University (dnr 03-260). Written informed consent was obtained from all IBD patients and oral informed consent was obtained from the healthy blood donors. 
Enzyme and metabolite assays

IMPDH activity was measured in peripheral blood mononuclear cells (MNC) with the ion-pair reversed-phase high-pressure liquid chromatography (HPLC) method previously described by Glander et al. [31] with minor modifications: MNC were isolated using cell prep tubes (CPT tubes $8 \mathrm{ml}$, 362782) from Becton Dickinson (Franklin Lakes, $\mathrm{NJ}$, USA) with two washing steps instead of Ficoll-Paque. The mobile phase had a higher concentration of tetrabutylammonium bisulphate than in the original method (14 $\mathrm{mm}$ instead of $7 \mathrm{~mm}$ ).

IMPDH activity was expressed as nmol xanthosine 5'-monophosphate (XMP) formed from inosine 5'monophosphate (IMP) per milligram protein and hour. The assay was run on a Dionex isocratic system (Sunnyvale, CA, USA) with the Chromeleon 6.40 software and an ASI-100 automated sampler, a P680 HPLC pump, and a UV/VIS UVD170U detector. A Prontosil 120-5-C18-AQ 5.0- $\mu \mathrm{m}$ column (Bishoff Chromatography, Leonberg, Germany) with a Brownlee NewGuard MPLC RP18 Aquapor precolumn (Perkin Elmer, Shelton, CT, USA) was utilized.

The standard curve comprised water solutions of XMP at concentrations ranging from 3.7 to $70.0 \mathrm{mmol} \mathrm{I}^{-1}$.

The sensitivity, specificity, linearity and imprecision were approximately as described by Glander et al. [31] with an imprecision $<7 \%$ in the incubation conditions.

IMP, nicotinamid adenine dinucleotide (NAD), XMP, KCI and $\mathrm{K}_{2} \mathrm{CO}_{3}$ were obtained from Sigma Aldrich (St Louis, $\mathrm{MO}$, USA), tetrabutylammonium bisulphate and $\mathrm{KH}_{2} \mathrm{PO}_{4}$ from Fluka (Buchs, Switzerland) and methanol from Labscan Analytical Sciences (Dublin, Ireland).

TPMT activity was determined in red blood cells (RBC) as previously described [32]. One unit of TPMT enzyme activity represents the formation of $1 \mathrm{nmol} 6$-methyl-MP from 6-MP per $\mathrm{ml}$ packed RBC and hour of incubation $\left(\mathrm{U} \mathrm{ml} l^{-1} \mathrm{pRBC}\right)$. The interassay coefficient of variation at $12 \mathrm{U} \mathrm{ml}^{-1}$ pRBC was 8.4\%. 6-TGN and meTIMP were determined by the method of Lennard and Singleton [33]. The lower limits of quantification of the 6-TGN and meTIMP assays were 20 and 300 pmol per $8 \times 10^{8} \mathrm{RBC}$, respectively. The interassay coefficients of variation at 62 and $692 \mathrm{pmol}$ 6 -TGN per $8 \times 10^{8}$ RBC were $21.3 \%$ and $18.9 \%$, respectively. The interassay coefficients of variation at 1670 and 17400 pmol meTIMP per $8 \times 10^{8}$ RBC were $30.3 \%$ and $27.4 \%$, respectively.

\section{DNA extraction and genotyping}

DNA was isolated using the Biorobot Ez1 and the Ez1 DNA blood kit (Qiagen, Hilden, Germany).The ITPA 94C $\rightarrow$ A polymorphism was determined using a pyrosequencing method for genotyping $[34,35]$.

\section{Statistical analysis}

Statistical analysis was performed using the Statistical Package for Social Sciences (SPSS, Inc., Chicago, IL, USA), version 14.0 for Windows.
When evaluating the results, 6-MP doses were converted to AZA doses assuming a conversion factor of 2.08 [36]. The dose-normalized metabolite concentrations were expressed as pmol metabolite per mg AZA. The data distribution for each variable was evaluated using the Kolmogorov-Smirnov test. Correlations between variables were evaluated using the Spearman rank order correlation coefficient, $r_{\mathrm{s}}$. For group comparisons, the Mann-Whitney $U$-test was used. Median (range) values are given. Twosided testing was used and considered statistically significant if $P<0.05$.

\section{Results}

\section{Healthy blood donors}

Intraindividual variation in IMPDH activity was investigated in three different subjects over time (four measurements during 1 month). IMPDH activity varied $<25 \%$ (CV) within each subject (data not shown). A wide range of IMPDH activity was observed among healthy blood donors with a median of $13.1 \mathrm{nmol} \mathrm{mg}^{-1} \mathrm{~h}^{-1}$ and a range of $4.7-$ $24.2 \mathrm{nmol} \mathrm{mg}^{-1} \mathrm{~h}^{-1}$ (Figure 1a). The distribution of IMPDH activity did not differ significantly from a normal distribution $(P=0.91)$.

\section{IBD patients}

Patient characteristics are summarized in Table 1. The median metabolite concentrations were 154.6 (39.2383.1) pmol 6-TGN per $8 \times 10^{8} \mathrm{RBC}$ and $1500(0-$ $11700)$ pmol meTIMP per $8 \times 10^{8} \mathrm{RBC}$.

In the IBD population the median IMPDH activity was 14.0 (7.0-21.7) $\mathrm{nmol} \mathrm{mg}^{-1} \mathrm{~h}^{-1}$ (Figure 1b). The distribution of IMPDH activity did not differ significantly from a normal distribution $(P=0.93)$. There was no significant difference in IMPDH activity between blood donors and IBD patients $(P=0.66)$.

No significant differences in IMPDH activity or metabolite concentrations were found between patients with UC and CD (data not shown).

There was no difference in meTIMP or 6-TGN concentrations, nor in TPMT and IMPDH activity between patients on concomitant 5-ASA therapy vs. those who were not $(P=0.47,0.86,0.24$ and 0.08 , respectively).

\section{Relationship between IMPDH and metabolite concentrations}

There was a negative correlation between IMPDH activity and meTIMP concentrations normalized to AZA dose $\left(r_{s}=-0.31, P=0.03\right)$, but no correlation with normalized 6-TGN concentrations $\left(r_{s}=-0.16, P=0.27\right)$ or the meTIMP/ 6-TGN ratio $\left(r_{s}=-0.25, P=0.08\right)$ (Figure 2 and Table 2 ). There was no correlation between IMPDH activity and TPMT activity $(P=0.71)$. When patients heterozygous for the ITPA $94 \mathrm{C} \rightarrow$ A polymorphism $(n=7)$ were excluded, results were essentially unchanged (Table 2 ). 
a

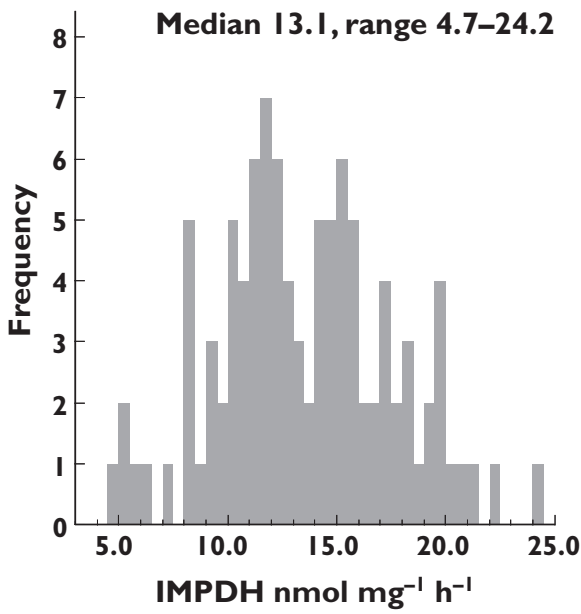

b

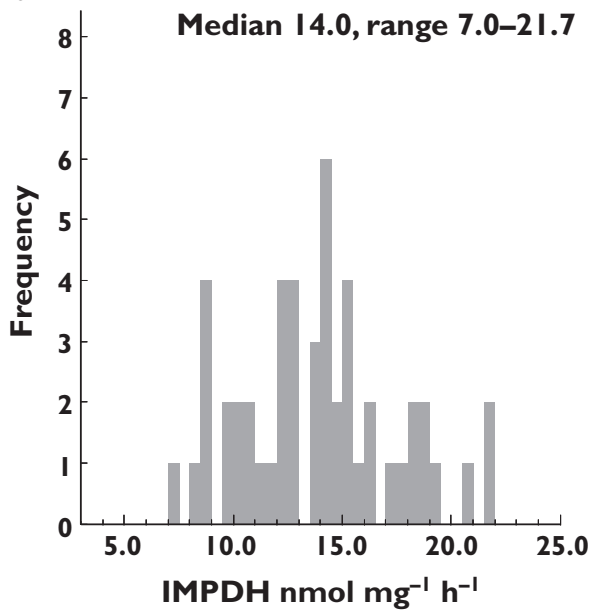

\section{Figure 1}

Inosine-5'-monophosphate dehydrogenase activity in (a) healthy blood donors, $n=100$ and (b) inflammatory bowel disease patients, $n=50$

\section{Remission or active disease}

Patients in clinical remission $(n=43)$ had higher 6-TGN concentrations than those with active disease [median $162.3(60.6-383.1)$ pmol per $8 \times 10^{8}$ RBC vs. 85.8 (39.2297.0) pmol per $\left.8 \times 10^{8} \mathrm{RBC}, P<0.05\right]$. Even if the numerical values of the meTIMP concentrations differed between these two groups, the difference was not statistically significant [median $1700(0-11700)$ pmol per $8 \times 10^{8}$ RBC vs. 200 (200-4800) pmol per $\left.8 \times 10^{8} \mathrm{RBC}, P=0.24\right]$. There was no correlation between metabolite concentrations and the Harvey-Bradshaw index in CD patients or the Walmsley index in UC patients (data not shown).

\section{Blood cell counts}

The metabolite concentrations did not correlate to the white blood cell counts (data not shown). Eight patients with high meTIMP concentrations ( $\geq 4800$ pmol per $8 \times 10^{8}$ RBC) had low but still normal monocyte and neutrophil cell counts compared with patients with lower meTIMP concentrations [median monocyte count $0.3(0.2-0.5) \times 10^{9}$ cells $\mathrm{I}^{-1}$ and neutrophil count $2.3(1.8-3.0) \times 10^{9}$ cells $\mathrm{I}^{-1} \mathrm{vs}$.

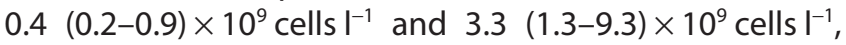
$P<0.05]$. There was no difference in lymphocyte counts $(P=0.18)$.

\section{Discussion}

In this first study of IMPDH activity in patients with IBD, those on stable thiopurine therapy were included and IMPDH and TPMT activity was related to thiopurine metabolite concentrations and clinical characteristics in order to elucidate the significance of IMPDH in the thiopurine metabolism. To compensate for differences in doses between patients, dose-normalized metabolite concentra- tions were used when investigating relationships between metabolite concentrations and metabolic capacity (enzymatic activities), as previous data from our group has demonstrated a linear relationship between dose and formation of meTIMP, using the same methodology as in this study [37]. However, when investigating for biological effects the measured metabolite concentration was used.

IMPDH activity was distributed over a wide range of activity both in healthy blood donors and in patients with IBD. Compared with the well-known trimodal distribution of TPMT activity, a similar genetic influence does not seem likely on the distribution of IMPDH activity. In the study by Roberts et al. [38], patients with high meTIMP concentrations resistant to thiopurine therapy were investigated for genetic variations in IMPDH1 and IMPDH2 compared with azathioprine-responsive patients. An insertion in the P3 promotor of IMPDH1 was observed in one patient with a reduced promoter activity as determined in vitro. Although IMPDH activity was not measured in the investigated patients, promoter variants offer one possible explanation for the wide range of IMPDH activity observed. However, the variants described are rare, and therefore not likely to explain the relatively high frequency of individuals with high or low activity. Also, it remains to be established whether or not an altered promoter activity is reflected in an altered expression level and enzyme activity of IMPDH.

The inverse relationship between IMPDH activity in MNC and dose-normalized meTIMP concentration in RBC is a new, but expected finding. However, 6-TGN concentrations did not correlate to IMPDH activity. Given that IMPDH is considered to be the rate-limiting step in the de novo purine synthesis in MNC $[18,19]$, and that RBC metabolite concentrations accurately reflect those in MNC, we had expected to find a positive relationship. This absence of a positive correlation between IMPDH activity and 6-TGN 


\section{Table 1}

Patient characteristics

\begin{tabular}{|c|c|}
\hline Patient characteristics & $n=50$ \\
\hline Disease (CD/UC) & $25 / 25$ \\
\hline Gender (female/male) & $27 / 23$ \\
\hline Age (years) & 37 (range 19-80) \\
\hline Remission/active disease & $43 / 7$ \\
\hline Corticosteroids (yes/no) & $7 / 43$ \\
\hline 5-ASA (yes/no) & $24 / 26$ \\
\hline AZA/6-MP & $39 / 11$ \\
\hline AZA dose $\left(\mathrm{mg} \mathrm{kg}^{-1} \mathrm{day}^{-1}\right)$ & $2.06(0.83-2.94)$ \\
\hline 6-MP dose $\left(\mathrm{mg} \mathrm{kg}^{-1} \mathrm{day}^{-1}\right)$ & $0.92(0.33-1.62)$ \\
\hline \multicolumn{2}{|l|}{ Indication for immunosuppression* } \\
\hline Relapses $>2$ times per year & 7 \\
\hline Steroid dependency & 16 \\
\hline Chronically active disease & 24 \\
\hline Intestinal fistulae & 1 \\
\hline Remission maintenance & 4 \\
\hline Postoperative prophylaxis & 2 \\
\hline IMPDH $\left(\mathrm{nmol} \mathrm{mg}^{-1} \mathrm{~h}^{-1}\right)$ & 14.0 (range $7.0-21.7$ ) \\
\hline TPMT (U ml-1 pRBC) & 11.4 (range 5.4-15.8) \\
\hline 6 -TGNt (pmol per $\left.8 \times 10^{8} \mathrm{RBC}\right)$ & 154.6 (range 39.2-383.1) \\
\hline meTIMP¥ (pmol per $8 \times 10^{8} \mathrm{RBC}$ ) & 1500 (range $0-11700$ ) \\
\hline WBC $\left(10^{9} \mathrm{I}^{-1}\right)$ & 4.7 (range $2.7-10.2$ ) \\
\hline Neutrophil count $\left(10^{9} \mathrm{I}^{-1}\right)$ & 2.8 (range $1.3-9.3$ ) \\
\hline Lymphocyte count $\left(10^{9} \mathrm{I}^{-1}\right)$ & 1.2 (range $0.4-2.7$ ) \\
\hline Thrombocyte count $\left(10^{9} \mathrm{I}^{-1}\right)$ & 278 (range 148-494) \\
\hline
\end{tabular}

*Four patients were categorized as having more than one indication for immunosupression. T6-TGN: The lowest calibrator is $20 \mathrm{pmol}$ per $8 \times 10^{8} \mathrm{RBC}$. If a result was reported as 'traces of $6-\mathrm{TGN}^{\prime}$ ' it was set to a concentration of $19 \mathrm{pmol}$ per $8 \times 10^{8} \mathrm{RBC}$. If 6 -TGN was reported as 'not detectable', the result was set to a concentration of $0 \mathrm{pmol}$ per $8 \times 10^{8} \mathrm{RBC}$. $\neq$ meTIMP: The lowest calibrator is $300 \mathrm{pmol}$ per $8 \times 10^{8} \mathrm{RBC}$. Numerical values reported $<300$ were accepted. When the concentration was reported as 'traces of meTIMP' it was set to a concentration of 200, and when reported as 'not detectable' it was set to a concentration of $0 \mathrm{pmol}$ per $8 \times 10^{8} \mathrm{RBC}$. Reference ranges: leucocyte count 3.5-8.8 $\times 10^{9} \mathrm{I}^{-1}$; neutrophil count $1.7-8.0 \times 10^{9} \mathrm{I}^{-1}$; lymphocyte count $1.1-4.8 \times 10^{9} \mathrm{I}^{-1}$; thrombocyte count, females $165-387 \times 10^{9} \mathrm{I}^{-1}$, males $145-$ $348 \times 10^{9} \mathrm{I}^{-1}$. CD, Crohn's disease; UC, ulcerative colitis; 5-ASA, 5-aminosalicylic acid; 6-MP, 6-mercaptopurine; IMPDH, inosine-5'-monophosphate dehydrogenase; TPMT, thiopurine S-methyltransferase; 6-TGN, 6-thioguanine nucleotide; meTIMP, 6-methylthioinosine 5'-monophosphate.

may be because either (i) thiopurine metabolites and IMPDH activity were measured in different cell types, or (ii) IMPDH is not as central as has been thought to the mechanism of action in vivo [6].

In clinical practice, RBC are routinely used for TPMT and metabolite measurements in the management of patients on thiopurine therapy. Therefore, these RBC assays were also performed in our study. The use of RBC as a surrogate marker for MNC is based on the fact that TPMT activity in $\mathrm{RBC}$ reflects that in lymphocytes and other tissues such as kidney, hepatic tissues and leukaemic blasts [39-42]. The concentration of thiopurine metabolites in RBC have been proposed to reflect the concentration in less accessible tissue such as the MNC [43].

IMPDH activity is very low in RBC lysates and, in fact, the enzyme has been suggested to be essentially nonfunc- tional in these cells [44]. We therefore used MNC as the compartment for IMPDH measurements. The absence of a positive correlation between IMPDH activity and 6-TGN may thus have been affected by the use of different biological compartments for determinations of the various enzyme activities and metabolite concentrations.

Since thiopurines are metabolized to 6-TGN via IMPDH, the absence of a positive correlation between MNC IMPDH activity and RBC 6-TGN in our study casts doubt on the use of RBC as a surrogate marker for MNC metabolite concentrations. $\mathrm{RBC}$ have been suggested as a relevant compartment for monitoring of thiopurine metabolites reflecting the metabolite content in the target cells, but the data supporting this are limited $[43,45]$. RBC lack the ability to synthesize nucleic acid, but they do have a high capacity for salvage of purine bases and nucleosides by HPRT [46, 47]. The 6-TGN concentrations found in circulating RBC have been suggested to be synthesized through salvage pathways of purine bases formed from hepatic metabolism or blood cell compartments other than RBC able to produce 6-TG and 6-TX [43,47-49]. Therefore 6-TGN levels in RBC do not necessarily reflect the metabolite status of the target cells correctly. This is further substantiated by the fact that only a weak positive correlation was observed between leucocyte DNA 6-TGN and RBC 6-TGN concentrations [50].

Ideally, all metabolite concentrations and enzyme activities should be measured in the same compartment, i.e. MNC as they present an active pathway for the synthesis of 6-TGN via IMPDH. To the best of our knowledge, no study has compared MNC IMPDH activity and MNC thiopurine metabolite concentrations in thiopurine-treated patients. Conversely, when Khalil et al. [51] demonstrated low IMPDH activity in RBC, the relationships between RBC IMPDH and RBC 6-TGN and between RBC IMPDH and MNC IMPDH were not investigated.

Besides the question concerning the validity of RBC as a surrogate compartment for MNC metabolite measurements, it is possible that IMPDH is not the rate-limiting enzyme in the conversion of thiopurine drugs to 6-TGN in MNC. Incubation of WEHI-3b cells with increasing 6-MP concentrations was accompanied by increased concentrations of TIMP and thio-XMP but, surprisingly, led to reduced concentrations of thio-GMP, thio-GDP and thio-GTP, as well as decreased de novo synthesis of ATP and GTP [52]. The concentration of meTIMP was not measured in that experiment. These findings indicate that it is not the regulation of only IMPDH, but also that of other pharmacogenes such as guanosine $5^{\prime}$-monophosphate synthetase, that is central to the production of 6-TGN [52]. Although it is possible that $\mathrm{IMPDH}$ is a rate-limiting enzyme under special circumstances, such as low or absent TPMT activity, our data do not support such a notion. However, this observation is based on only four patients with intermediate TPMT activity (5.4-8.7 $\left.\mathrm{U} \mathrm{ml}^{-1} \mathrm{pRBC}\right)$. In these four subjects, greater MNC IMPDH activity did not correspond to a higher RBC 

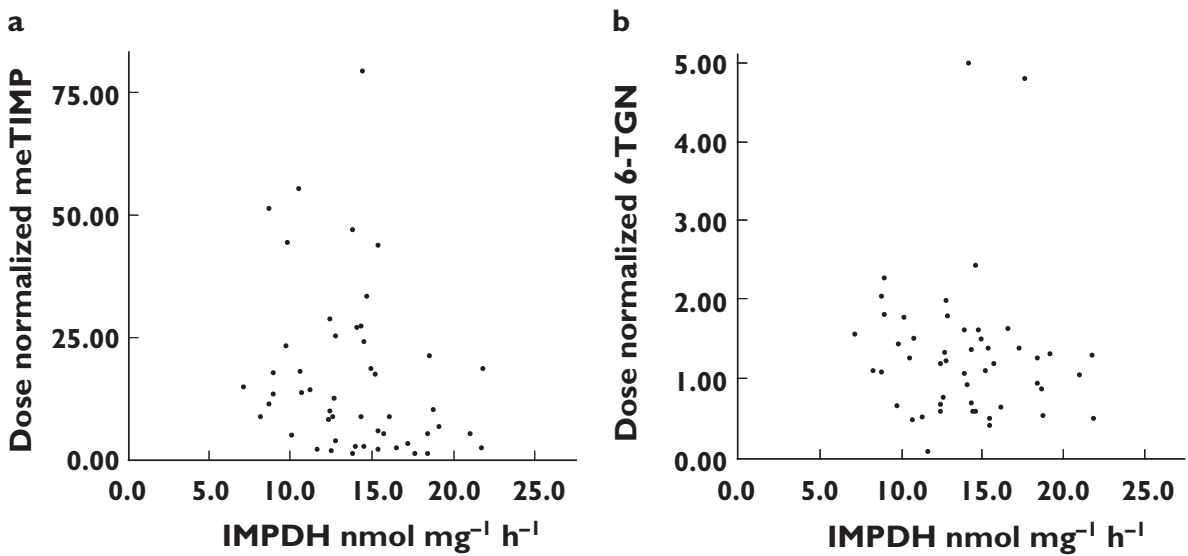

\section{Figure 2}

Inflammatory bowel disease patients, $n=50$. (a) A scatterplot of inosine-5'-monophosphate dehydrogenase (IMPDH) activity and 6-methylthioinosine $5^{\prime}$-monophosphate concentrations normalized to azathioprine dose $\left(r_{s}=-0.31, P=0.03\right)$. (b) A scatterplot of IMPDH activity and dose-normalized 6-thioguanine nucleotide concentrations $\left(r_{\mathrm{s}}=-0.16, P=0.27\right)$

\section{Table 2}

Relationships between IMPDH and TPMT activities and *dose-normalized metabolite concentrations in 50 inflammatory bowel disease patients

\begin{tabular}{|c|c|c|c|c|c|c|}
\hline & \multicolumn{2}{|c|}{$\begin{array}{l}\text { IMPDH activity } \mathrm{nmol} \mathrm{mg}^{-1} \mathrm{~h}^{-1} \\
(n=50)\end{array}$} & \multicolumn{2}{|c|}{$\begin{array}{l}\text { IMPDH activity in wild-type ITPA } \\
\text { patients } \mathrm{nmol} \mathrm{mg}^{-1} \mathrm{~h}^{-1}(n=43)\end{array}$} & \multicolumn{2}{|c|}{$\begin{array}{l}\text { TPMT activity } \mathrm{U} \mathrm{ml}^{-1} \\
\text { packed } \mathrm{RBC}(n=50)\end{array}$} \\
\hline & $r_{\mathrm{s}}$ & $P$ & $r_{\mathrm{s}}$ & $P$ & $r_{\mathrm{s}}$ & $P$ \\
\hline 6-TGN & -0.16 & 0.27 & -0.14 & 0.38 & 0.23 & 0.11 \\
\hline Ratio of meTIMP/6-TGN & -0.25 & 0.08 & -0.27 & 0.09 & -0.03 & 0.82 \\
\hline TPMT activity & -0.05 & 0.71 & -0.22 & 0.16 & - & - \\
\hline
\end{tabular}

*The dose-normalized metabolite concentrations are expressed as pmol metabolite per mg AZA. IMPDH, inosine-5'-monophosphate dehydrogenase; ITPA, inosine triphosphate pyrophosphatase; TPMT, thiopurine S-methyltransferase; meTIMP, 6-methylthioinosine 5'-monophosphate; 6-TGN, 6-thioguanine nucleotide.

6-TGN concentration and the range of 6-TGN concentrations measured did not differ from that in patients with normal TPMT activity (data not shown).

Although measured in the same compartment, RBC, no correlation was observed between TPMT and dosenormalized 6-TGN, normalized meTIMP or the meTIMP/6TGN ratio. These findings are supported by some [32,53] but not all $[7,37,54]$ studies. The absence of correlations might have been effected by the coadministration of 5-ASA in 24 patients [55]. However, neither meTIMP or 6-TGN concentrations or the activities of TPMT and IMPDH differed between patients with and without concomitant 5-ASA.

\section{Role of ITPA}

It has been suggested that the ITPA $94 \mathrm{C} \rightarrow$ A polymorphism could be associated with adverse events in patients treated with thiopurines $[14-16,56]$. This has, however, not been confirmed by others [17,57-60].In these studies the thiopurine metabolite pattern was not described in association with the ITPA genotype. In our study, only seven subjects were heterozygous for the ITPA $94 \mathrm{C} \rightarrow \mathrm{A}$ polymorphism.
Although our data are limited, it does not seem likely that the heterozygosity had any effect on the relationships investigated, since the metabolite concentrations did not differ between the heterozygotes and the wildtypes in the patient population studied (data not shown).

\section{Thiopurine metabolism and clinical effects}

The 43 patients in clinical remission had higher 6-TGN concentrations than those with active disease. The 6-TGN concentrations in patients in remission were, however, lower than those described by others [61]. In one study no difference was observed between patients with active and quiescent disease [60]. Six out of seven patients with active disease had relatively low metabolite concentrations $\left(6-\mathrm{TGN} \leq 125 \mathrm{pmol}\right.$ per $8 \times 10^{8} \mathrm{RBC}$ and meTIMP $\leq 4800$ pmol per $8 \times 10^{8} \mathrm{RBC}$ ) in combination with normal enzymatic activities $(n=5)$, indicating noncompliance, resistance to thiopurine therapy or suboptimal dosing. One of the subjects had intermediate TPMT activity and one had active disease despite adequate metabolite concentrations. 


\section{Conclusion}

Even if this study has shown a negative correlation between IMPDH activity and the formation of meTIMP, we could not demonstrate a clear-cut role for IMPDH as an important rate-limiting enzyme in balancing the formation of methylated and phosphorylated thiopurine metabolites. Our results indicate either that RBC is not a good surrogate cellular compartment for MNC, when assaying for thiopurine metabolites in relation to IMPDH activity, or that IMPDH is not the important rate-limiting enzyme in MNC in the interconversion of thioinosine monophosphate to 6-TGN, as has been hypothesized. Taken together, our results give cause to question established opinions about thiopurine metabolism. Preferably, all metabolite concentrations and enzyme activities should be measured in the same compartment, i.e. MNC, as these cells display an intact metabolic pathway from 6-MP to 6-TGN.

\section{Competing interests: None declared.}

We thank the physicians who kindly contributed patients to this study, especially Christer Grännö, and the nurses Monika Wåhlin and Anette Persson, County Hospital Ryhov, Jönköping, for valuable help. We also thank Britt Sigfridsson and Lena Svensson for excellent technical assistance with the assessment of TPMT enzymatic activity, metabolite measurements and ITPA genotypning. Parts of these results were presented in abstract form at the 10th symposium European Society for the Study of Purine and Pyrimidine Metabolism in Man (Prague, Czech Republic) and the 13th United European Gastroenterology week (Copenhagen, Denmark) 2005. The study was performed with financial support from: Futurum The Academy of Healthcare, County Council, Jönköping; The Research Council in the South-east of Sweden (FORSS), grants F2000-312, P2001-303, F2002-304, F2003-340, F2003-306; Rut and Richard Juhlin's foundation 2003; The Swedish Medical Society, grant 2004-685; The Swedish Research Council, grant 2005-19523-30873-57; The Swedish Cancer Society, contract 05 0436; The Swedish Children's Cancer Society, project 03/069.

\section{REFERENCES}

1 Sandborn WJ. Therapy for Crohn's disease. Curr Opin Gastroenterol 2000; 16: 318-23.

2 Hanauer SB. Medical therapy for ulcerative colitis. Curr Opin Gastroenterol 2000; 16: 324-8.

3 Sandborn WJ. Steroid-dependent Crohn's disease. Can J Gastroenterol 2000; 14 (Suppl. C): 17C-22C.

4 Feagan BG. Maintenance therapy for inflammatory bowel disease. Am J Gastroenterol 2003; 98: S6-S17.

5 Belaiche J, Desager JP, Horsmans Y, Louis E. Therapeutic drug monitoring of azathioprine and 6-mercaptopurine metabolites in Crohn disease. Scand J Gastroenterol 2001; 36: 71-6.

6 Elion GB. Symposium on immunosuppressive drugs. Biochemistry and pharmacology of purine analogues. Fed Proc 1967; 26: 898-904.

7 Lennard L, Lilleyman JS, Van Loon J, Weinshilboum RM. Genetic variation in response to 6-mercaptopurine for childhood acute lymphoblastic leukaemia. Lancet 1990; 336: 225-9.

8 Hill DL, Bennett LL Jr. Purification and properties of 5-phosphoribosyl pyrophosphate amidotransferase from adenocarcinoma 755 cells. Biochemistry 1969; 8: 122-30.

9 Tay BS, Lilley RM, Murray AW, Atkinson MR. Inhibition of phosphoribosyl pyrophosphate amidotransferase from Ehrlich ascites-tumour cells by thiopurine nucleotides. Biochem Pharmacol 1969; 18: 936-8.

10 Bennett LL Jr, Allan PW. Formation and significance of 6-methylthiopurine ribonucleotide as a metabolite of 6-mercaptopurine. Cancer Res 1971; 31: 152-8.

11 Bokkerink JP, Stet EH, De Abreu RA, Damen FJ, Hulscher TW, Bakker MA, van Baal JA. 6-Mercaptopurine: cytotoxicity and biochemical pharmacology in human malignant T-lymphoblasts. Biochem Pharmacol 1993; 45: 1455-63.

12 Atreya I, Neurath MF. Thiopurines in inflammatory bowel disease - recent insights. Inflamm Bowel Dis Monit 2006; 7: 50-5.

13 Thomas CW, Myhre GM, Tschumper R, Sreekumar R, Jelinek D, McKean DJ, Lipsky JJ, Sandborn WJ, Egan LJ. Selective inhibition of inflammatory gene expression in activated T lymphocytes: a mechanism of immune suppression by thiopurines. J Pharmacol Exp Ther 2005; 312: 537-45.

14 Marinaki AM, Ansari A, Duley JA, Arenas M, Sumi S, Lewis CM, el Shobowale-Bakre M, Escuredo E, Fairbanks LD, Sanderson JD. Adverse drug reactions to azathioprine therapy are associated with polymorphism in the gene encoding inosine triphosphate pyrophosphatase (ITPase). Pharmacogenetics 2004; 14: 181-7.

15 Marinaki AM, Duley JA, Arenas M, Ansari A, Sumi S, Lewis CM, Shobowale-Bakre M, Fairbanks LD, Sanderson J. Mutation in the ITPA gene predicts intolerance to azathioprine. Nucleosides Nucleotides Nucl Acids 2004; 23: 1393-7.

16 Zelinkova Z, Derijks LJ, Stokkers PC, Vogels EW, van Kampen $\mathrm{AH}$, Curvers WL, Cohn D, van Deventer SJ, Hommes DW. Inosine triphosphate pyrophosphatase and thiopurine s-methyltransferase genotypes relationship to azathioprine-induced myelosuppression. Clin Gastroenterol Hepatol 2006; 4: 44-9.

17 Gearry RB, Roberts RL, Barclay ML, Kennedy MA. Lack of association between the ITPA 94C $>$ A polymorphism and adverse effects from azathioprine. Pharmacogenetics 2004; 14: 779-81.

18 Jackson RC, Weber G, Morris HP. IMP dehydrogenase, an enzyme linked with proliferation and malignancy. Nature 1975; 256: 331-3. 
19 Weber G. Biochemical strategy of cancer cells and the design of chemotherapy: G. H. A. Clowes Memorial Lecture. Cancer Res 1983; 43: 3466-92.

20 Natsumeda Y, Ohno S, Kawasaki H, Konno Y, Weber G, Suzuki K. Two distinct cDNAs for human IMP dehydrogenase. J Biol Chem 1990; 265: 5292-5.

$21 \mathrm{Gu} J$ J, Kaiser-Rogers K, Rao K, Mitchell BS. Assignment of the human type I IMP dehydrogenase gene (IMPDH1) to chromosome 7q31.3-q32. Genomics 1994; 24: 179-81.

22 Glesne D, Collart F, Varkony T, Drabkin H, Huberman E. Chromosomal localization and structure of the human type II IMP dehydrogenase gene (IMPDH2). Genomics 1993; 16: 274-7.

23 Kost-Alimova MV, Glesne DA, Huberman E, Zelenin AV. Assignment1 of inosine'-monophosphate dehydrogenase type 2 (IMPDH2) to human chromosome band 3p21.2 by in situ hybridization. Cytogenet Cell Genet 1998; 82: 145-6.

24 Senda M, Natsumeda Y. Tissue-differential expression of two distinct genes for human IMP dehydrogenase (E.C.1.1.1.205). Life Sci 1994; 54: 1917-26.

25 Collart FR, Chubb CB, Mirkin BL, Huberman E. Increased inosine-5'-phosphate dehydrogenase gene expression in solid tumor tissues and tumor cell lines. Cancer Res 1992; 52: 5826-8.

26 Zimmermann AG, Gu JJ, Laliberté J, Mitchell BS. Inosine-5'-monophosphate dehydrogenase: regulation of expression and role in cellular proliferation and $\mathrm{T}$ lymphocyte activation. Prog Nucl Acid Res Mol Biol 1998; 61: 181-209.

27 Kiguchi K, Collart FR, Henning-Chubb C, Huberman E. Induction of cell differentiation in melanoma cells by inhibitors of IMP dehydrogenase: altered patterns of IMP dehydrogenase expression and activity. Cell Growth Differ 1990; 1: 259-70.

28 Natsumeda Y, Carr SF. Human type I and II IMP dehydrogenases as drug targets. Ann NY Acad Sci 1993; 696: 88-93.

29 Walmsley RS, Ayres RC, Pounder RE, Allan RN. A simple clinical colitis activity index. Gut 1998; 43: 29-32.

30 Harvey RF, Bradshaw JM. A simple index of Crohn's-disease activity. Lancet 1980; 1:514.

31 Glander P, Braun KP, Hambach P, Bauer S, Mai I, Roots I, Waiser J, Fritsche L, Neumayer HH, Budde K. Non-radioactive determination of inosine $5^{\prime}$-monophosphate dehydro-genase (IMPDH) in peripheral mononuclear cells. Clin Biochem 2001; 34: 543-9.

32 Pettersson B, Almer S, Albertioni F, Soderhall S, Peterson C. Differences between children and adults in thiopurine methyltransferase activity and metabolite formation during thiopurine therapy: possible role of concomitant methotrexate. Ther Drug Monit 2002; 24: 351-8.

33 Lennard L, Singleton HJ. High-performance liquid chromatographic assay of the methyl and nucleotide metabolites of 6-mercaptopurine: quantitation of red blood cell 6-thioguanine nucleotide, 6-thioinosinic acid and 6-methylmercaptopurine metabolites in a single sample. J Chromatogr 1992; 583: 83-90.

34 Marsh S, King CR, Ahluwalia R, McLeod HL. Distribution of ITPA P32T alleles in multiple world populations. J Hum Genet 2004; 49: 579-81.

35 Lindqvist M, Haglund S, Almer S, Peterson C, Taipalensuu J, Hertervig $E$, Lyrenas $E$, Soderkvist P. Identification of two novel sequence variants affecting thiopurine methyltransferase enzyme activity. Pharmacogenetics 2004; 14: $261-5$.

36 Sandborn WJ. A review of immune modifier therapy for inflammatory bowel disease: azathioprine, 6-mercaptopurine, cyclosporine, and methotrexate. Am J Gastroenterol 1996; 91:423-33.

37 Hindorf U, Peterson C, Almer S. Assessment of thiopurine methyltransferase and metabolite formation during thiopurine therapy: results from a large Swedish patient population. Ther Drug Monit 2004; 26: 673-8.

38 Roberts RL, Gearry RB, Barclay ML, Kennedy MA. IMPDH1 promoter mutations in a patient exhibiting azathioprine resistance. Pharmacogenomics 2006; Epub ahead of print. doi:10.1038/sj.tpj.6500421.

39 Van Loon JA, Weinshilboum RM. Thiopurine methyltransferase biochemical genetics: human lymphocyte activity. Biochem Genet 1982; 20: 637-58.

40 Szumlanski CL, Honchel R, Scott MC, Weinshilboum RM. Human liver thiopurine methyltransferase pharmacogenetics: biochemical properties, liver-erythrocyte correlation and presence of isozymes. Pharmacogenetics 1992; 2: 148-59.

41 Coulthard SA, Howell C, Robson J, Hall AG. The relationship between thiopurine methyltransferase activity and genotype in blasts from patients with acute leukemia. Blood 1998; 92: 2856-62.

42 McLeod HL, Relling MV, Liu Q, Pui CH, Evans WE. Polymorphic thiopurine methyltransferase in erythrocytes is indicative of activity in leukemic blasts from children with acute lymphoblastic leukemia. Blood 1995; 85: 1897-902.

43 Bergan S, Bentdal O, Sodal G, Brun A, Rugstad HE, Stokke O. Patterns of azathioprine metabolites in neutrophils, lymphocytes, reticulocytes, and erythrocytes: relevance to toxicity and monitoring in recipients of renal allografts. Ther Drug Monit 1997; 19: 502-9.

44 Montero C, Duley JA, Fairbanks LD, McBride MB, Micheli V, Cant AJ, Morgan G. Demonstration of induction of erythrocyte inosine monophosphate dehydrogenase activity in Ribavirin-treated patients using a high performance liquid chromatography linked method. Clin Chim Acta 1995; 238: 169-78.

45 Lancaster DL, Patel N, Lennard L, Lilleyman JS. Leucocyte versus erythrocyte thioguanine nucleotide concentrations in children taking thiopurines for acute lymphoblastic leukaemia. Cancer Chemother Pharmacol 2002; 50: 33-6.

46 Parks RE Jr, Crabtree GW, Kong CM, Agarwal RP, Agarwal KC, Scholar EM. Incorporation of analog purine nucleosides into 
the formed elements of human blood: erythrocytes, platelets, and lymphocytes. Ann NY Acad Sci 1975; 255: 412-34.

47 Duley JA, Florin TH. Thiopurine therapies: problems, complexities, and progress with monitoring thioguanine nucleotides. Ther Drug Monit 2005; 27: 647-54.

48 Rowland K, Lennard L, Lilleyman JS. In vitro metabolism of 6-mercaptopurine by human liver cytosol. Xenobiotica 1999; 29: 615-28.

49 Rostami-Hodjegan A, Lennard L, Lilleyman JS. The accumulation of mercaptopurine metabolites in age fractionated red blood cells. Br J Clin Pharmacol 1995; 40: 217-22.

50 Cuffari C, Seidman EG, Latour S, Theoret Y. Quantitation of 6-thioguanine in peripheral blood leukocyte DNA in Crohn's disease patients on maintenance 6-mercaptopurine therapy. Can J Physiol Pharmacol 1996; 74: 580-5.

51 Khalil PN, Erb N, Khalil MN, Escherich G, Janka-Schaub GE. Validation and application of a high-performance liquid chromatographic-based assay for determination of the inosine $5^{\prime}$-monophosphate dehydrogenase activity in erythrocytes. J Chromatogr B Anal Technol Biomed Life Sci 2006; 842: 1-7.

52 Liliemark J, Pettersson B, Engberg B, Lafolie P, Masquelier M, Peterson C. On the paradoxically concentration-dependent metabolism of 6-mercaptopurine in WEHI-3b murine leukemia cells. Cancer Res 1990; 50: 108-12.

53 Dubinsky MC, Yang $H$, Hassard PV, Seidman EG, Kam LY, Abreu MT, Targan SR, Vasiliauskas EA. 6-MP metabolite profiles provide a biochemical explanation for 6-MP resistance in patients with inflammatory bowel disease. Gastroenterology 2002; 122: 904-15.

54 Lennard L, Lilleyman JS. Individualizing therapy with 6-mercaptopurine and 6-thioguanine related to the thiopurine methyltransferase genetic polymorphism. Ther Drug Monit 1996; 18: 328-34.

55 Shipkova M, Niedmann PD, Armstrong VW, Oellerich M, Wieland E. Determination of thiopurine methyltransferase activity in isolated human erythrocytes does not reflect putative in vivo enzyme inhibition by sulfasalazine. Clin Chem 2004; 50: 438-41.

56 von Ahsen N, Armstrong VW, Behrens C, von Tirpitz C, Stallmach A, Herfarth H, Stein J, Bias P, Adler G, Shipkova M, Oellerich M, Kruis W, Reinshagen M. Association of inosine triphosphatase $94 \mathrm{C}>\mathrm{A}$ and thiopurine S-methyltransferase deficiency with adverse events and study drop-outs under azathioprine therapy in a prospective Crohn disease study. Clin Chem 2005; 51: 2282-8.

57 van Dieren JM, van Vuuren AJ, Kusters JG, Nieuwenhuis EE, Kuipers EJ, van der Woude CJ. ITPA genotyping is not predictive for the development of side effects in AZA treated inflammatory bowel disease patients. Gut 2005; 54: 1664.

58 Allorge D, Hamdan R, Broly F, Libersa C, Colombel JF. ITPA genotyping test does not improve detection of Crohn's disease patients at risk of azathioprine/6-mercaptopurine induced myelosuppression. Gut 2005; 54: 565.

59 De Ridder L, Van Dieren JM, Van Deventer HJ, Stokkers PC, Van der Woude JC, Van Vuuren AJ, Benninga MA, Escher JC, Hommes DW. Pharmacogenetics of thiopurine therapy in paediatric IBD patients. Aliment Pharmacol Ther 2006; 23: 1137-41.

60 Hindorf U, Lindqvist M, Peterson C, Soderkvist P, Strom M, Hjortswang $\mathrm{H}$, Pousette A, Almer S. Pharmacogenetics during standardised initiation of thiopurine treatment in inflammatory bowel disease. Gut 2006; 55: 1423-31.

61 Osterman MT, Kundu R, Lichtenstein GR, Lewis JD. Association of 6-thioguanine nucleotide levels and inflammatory bowel disease activity: a meta-analysis. Gastroenterology 2006; 130: 1047-53. 